\title{
Numerical analysis of tsunami propagation on wide reef platform
}

\author{
Takahito Mikami and Tomoya Shibayama
}

\section{Introduction}

- During the 2009 Samoan Islands Tsunami, the wide coral reef platform in front of the islands affected the approaching tsunami behavior (Mikami et al., 2011).

- This research aims to understand the characteristics of a tsunami propagating over a reef platform by using a turbulence model.

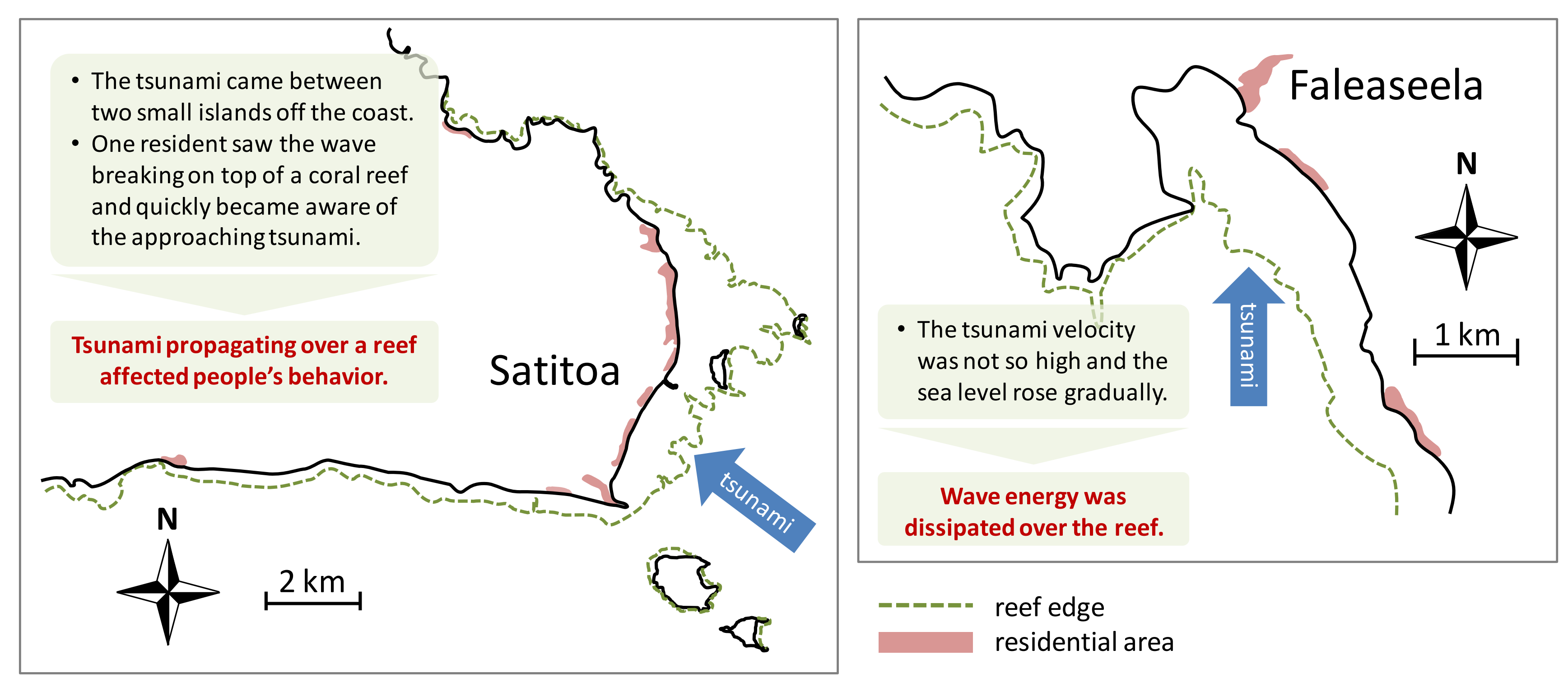

Fig. 1 Map of the surveyed villages in Upole Island, Samoa.

\section{Numerical model and results}

- A Large Eddy Simulation (LES) model was used to simulate wave breaking and energy dissipation.

- If a reef is wide enough, wave is divided into two peaks and then the wave height gradually decreases.

- The energy evaluated by the averaged energy flux is dissipated as the wave approaches the shoreline.

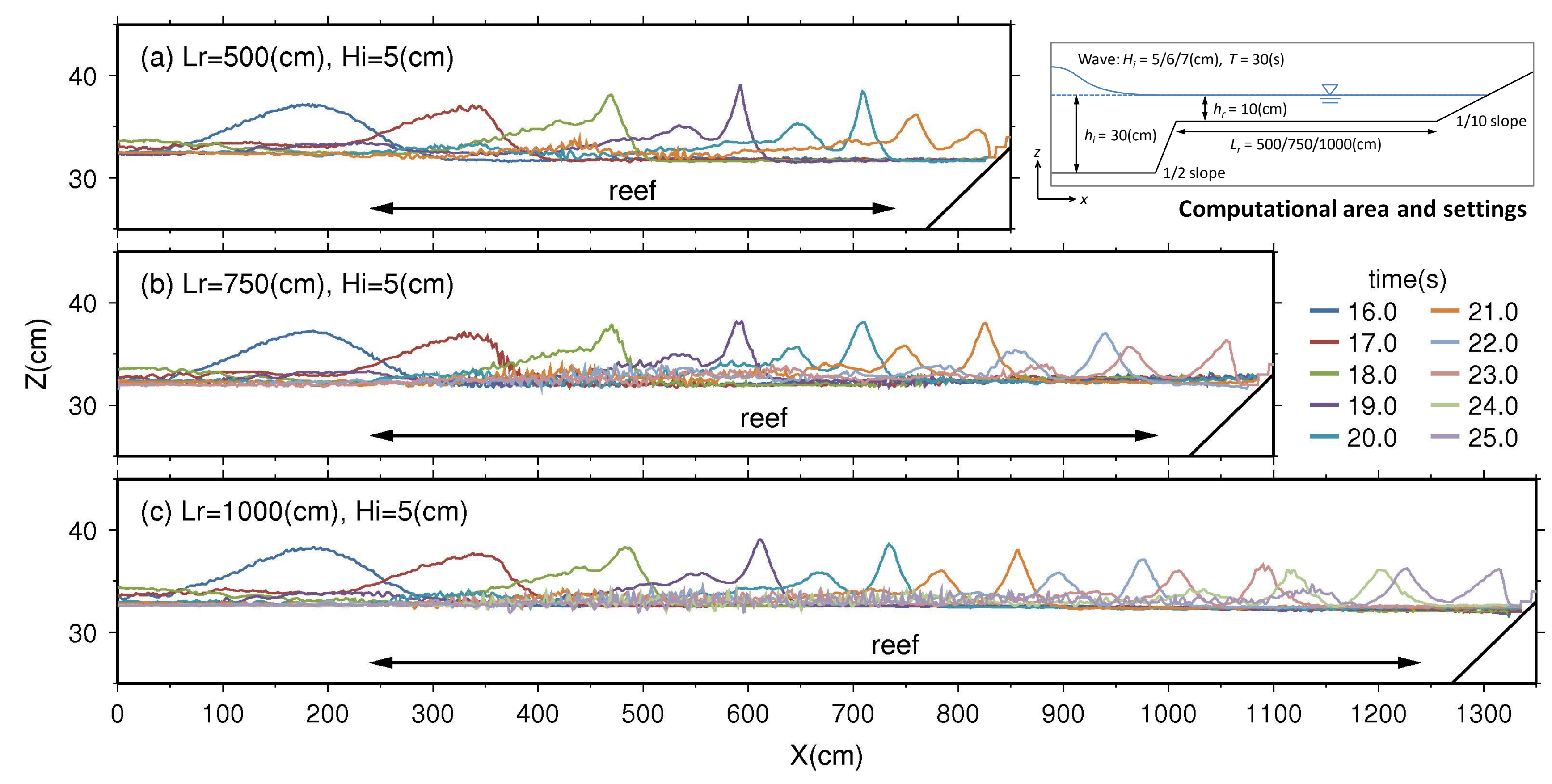

Fig. 3 Wave transformation over reef platforms.

\section{Conclusion}

- The results of numerical simulations by using LES model were shown to reproduce well the results of the field survey in the 2009 Samoan Islands Tsunami.

- The present method may also apply to other countries which have coral reefs and contribute to regional tsunami mitigation strategies.

- It is important to understand what is the phenomenon that people in coastal areas actually experience as well as the height and arrival time of a tsunami.

\section{Coral reef and tsunami}

- After the 2004 Indian Ocean Tsunami, the fact that coral reefs affected tsunami propagation was reported in many countries.

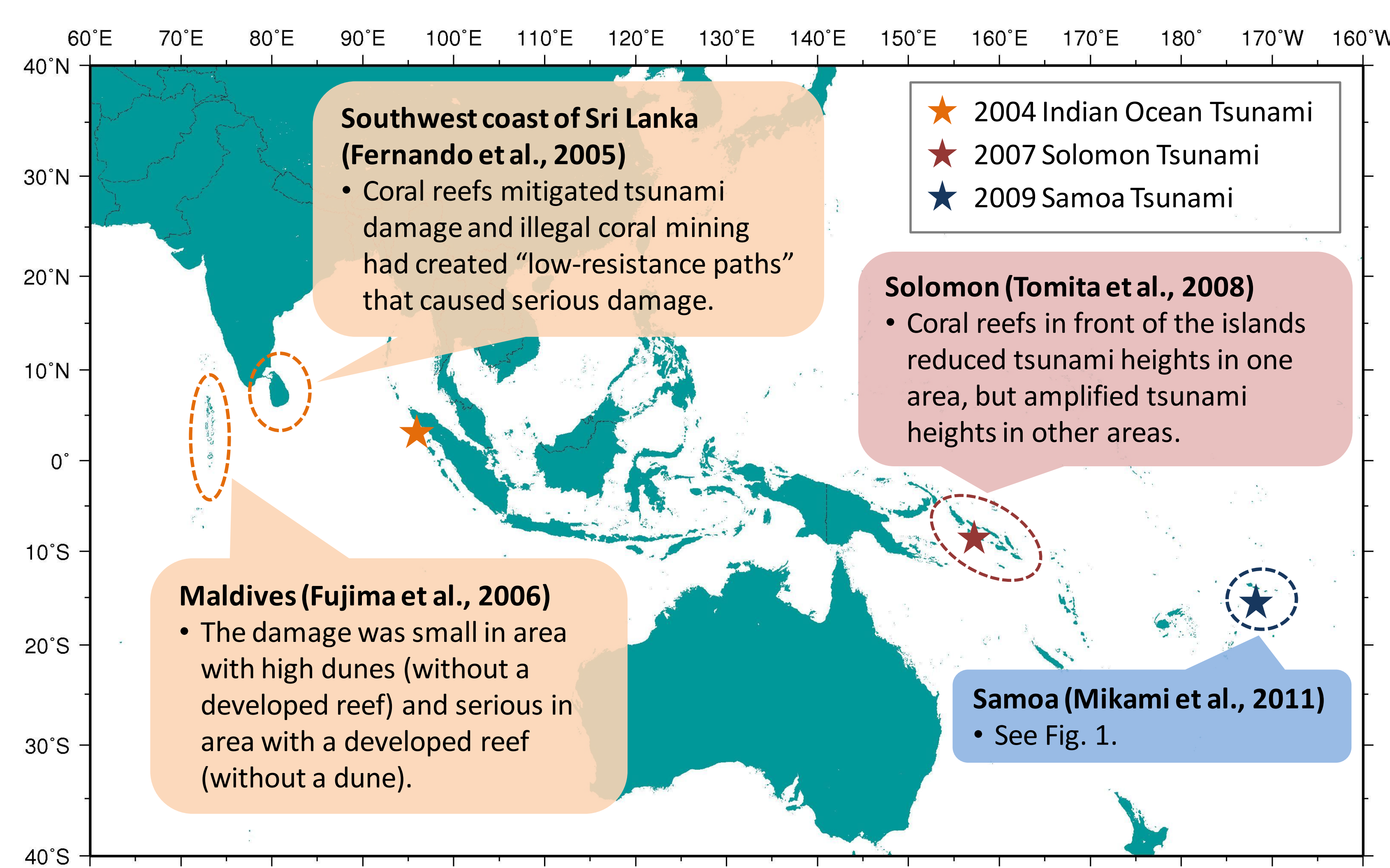

Fig. 2 Reported reef effects on previous tsunami events.
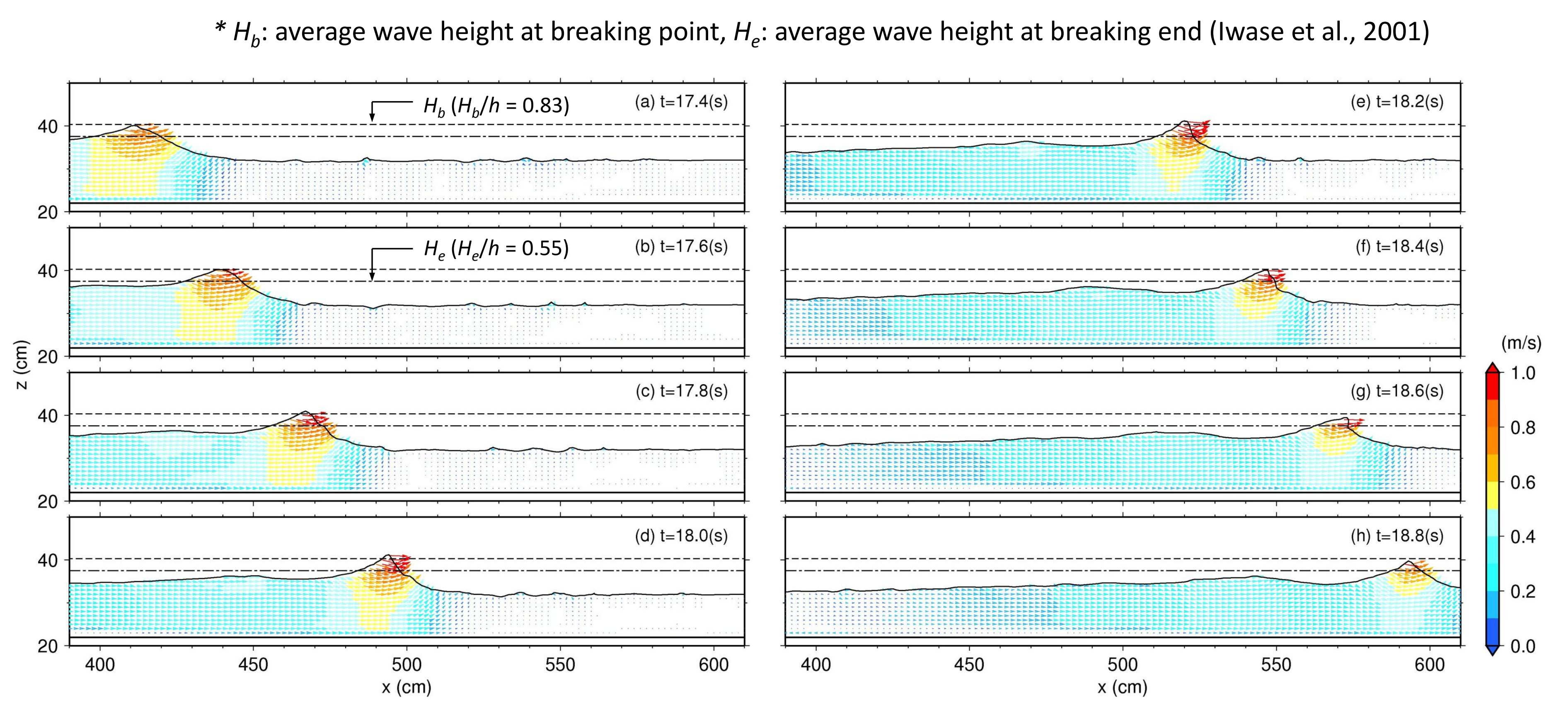

Fig. 4 Velocity field around breaking point $\left(L_{r}=750 \mathrm{~cm}, H_{i}=7 \mathrm{~cm}\right)$.
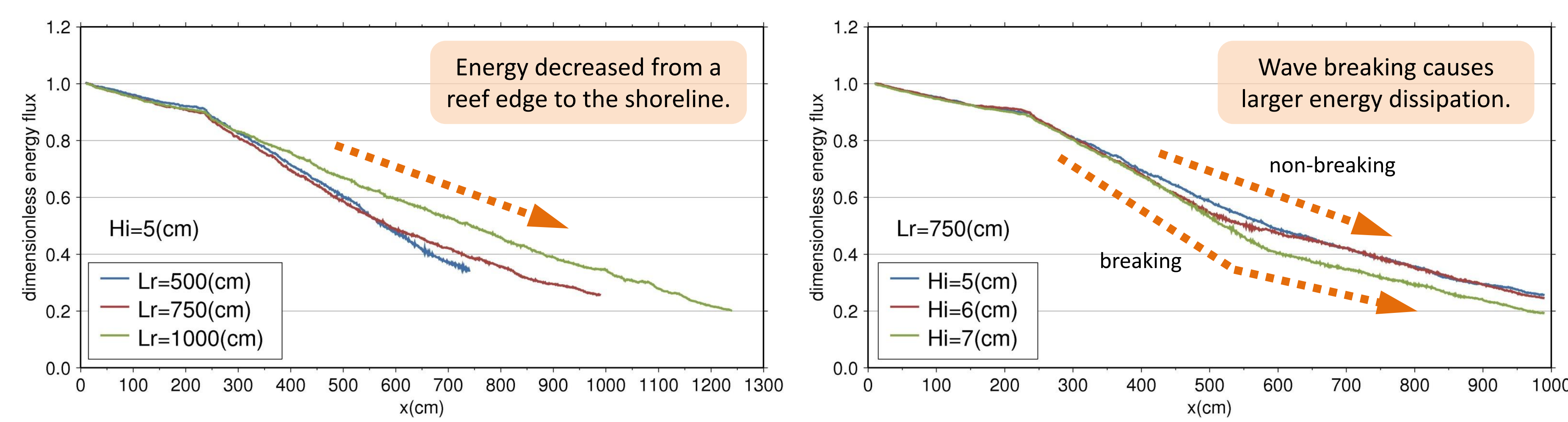

Fig. 5 Energy dissipation over reef platforms.

References

Fernando, H. J. S. et al. (2005): Coral poaching worsens tsunami destruction in Sri Lanka, Eos Trans., AGU, 86(33), pp.301, 304

Fujima, K. et al. (2006): Survey results of the Indian Ocean Tsunami in the Maldives, Coastal Engineering Journal, JSCE, 48(2), pp.81-97.

Iwase et al. (2001): Numerical simulation and hydraulic experiment on soliton fission and wave breaking, Proc. Coastal Engineering, JSCE, 48, pp.306-310. (in Japanese)

Mikami, T. et al. (2011): Field survey and analysis of tsunami disaster in the Samoan Islands 2009 Proc. 6th Int. Conf. Coastal Structures, in press.

Tomita, T. et al. (2008): Report of field survey on 2007 Solomon Islands Tsunami, Technical Note of PARI, No.1179, 41p. (in Japanese with English abstract)

\section{Contact}

Waseda University, Tokyo, Japan

- Takahito Mikami : t.mikami@asagi.waseda.jp 